\title{
Creation of a "Cosmic" Human: Ideas, Technologies, Projects, Experience, Risks, Limitations, and Prospects
}

\author{
Sergey Krichevsky \\ Doctor of Philosophical Sciences, Professor, Chief Researcher, S.I. Vavilov Institute \\ of the History of Science and Technology of the RAS \\ (Moscow, Russia) \\ E-mail:svkrich@mail.ru \\ https://orcid.org/0000-0002-1094-7770
}

Krichevsky, Sergey (2020) Creation of a "Cosmic” Human: Ideas, Technologies, Projects, Experience, Risks, Limitations, and Prospects. Future Human Image, Volume 13, 2020: 32-45. https://doi.org/10.29202/fhi/13/4

The article discusses the theoretical and practical aspects of the problem of creating a new "cosmic" human in the paradigm of space exploration and the creation of cosmic humanity. The solution to this problem is the key one for the future human and humanity in order for our civilization to survive and develop within the scope "Earth + Space." The definition of a "cosmic" human is given, and the periodization of the process of their creation in the form of four stages is made. The prototype of the "cosmic" human was created as a result of 60 years' experience (since 1959) in the selection, training, space flights, and off Earth long-term life of astronauts from the USA, the USSR, Russia, the EU and other countries. Significant results were obtained, but the limitations were recognized: human properties and characteristics, existing risks, and technologies so far limit the time of continuous safe stay in space (up to $\sim 1.5$ years), the scale and pace of its exploration. For further expansion into space, it is necessary to go beyond these limits, ensure safety, develop and transform humans using new technologies. The main issues are brought on the agenda of the 20s-50s of the $21^{\text {st }}$ century, i.e., the birth of children and permanent life of people in new space settlements in near-Earth space, on the Moon and Mars. A brief analysis of the main ideas, technologies, projects, experience, risks, limitations, prospects for the creation and evolution of the "cosmic" human is made. The conclusions are formulated.

Keywords: "cosmic" human, astronaut, limitation, experience, space exploration, prospect, birth in space, technology, evolution

Received: January 12, 2020; accepted: February 18, 2020

(C) Krichevsky, Sergey, 2020 


\section{Introduction}

In the paradigm of space exploration and the creation of cosmic humanity, following the research and publications in this area, we briefly consider the theoretical and practical aspects of the problem of creating a "cosmic" human as the basis of a new concept. ${ }^{1}$

Space exploration has a super task: the creation of cosmic humanity in the future for the purpose of the survival and development of humans and our entire civilization within the scope "Earth + Space." To do this, people need new space flights in the Solar System and beyond, but most importantly, it is necessary to create a new "cosmic" human, and this process is already underway.

"Cosmic" human is the next stage in the evolution of the "terrestrial" homo sapiens and their expansion beyond Earth for permanent life in space.

The prototype, the current model of the "cosmic" human, were created as a result of 60 years of experience ${ }^{2}$ in the selection, preparation, space flights, long-term life beyond the Earth of astronauts of the USA, the USSR, Russia, the EU, China and other countries with the participation of about 100 thousand people, $\sim 1000$ of them were selected and prepared for

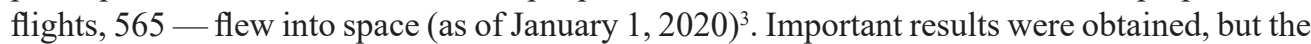
limitation of safe continuous human stay in space was recognized, reaching up to $\sim 1.5$ years with existing technologies. See section 2 for more details.

For further expansion into space, it is necessary to go beyond these limits, reduce the risks and ensure a higher level of safety, create comfortable living conditions, develop and possibly transform humans using new technologies.

A new, third period of the Space Age begins ${ }^{4}$, the issues on the agenda of the $20 \mathrm{~s}-50 \mathrm{~s}$ of the $21^{\text {st }}$ century focus on the birth of children and the permanent life of people in new space settlements in near-Earth space, on the Moon and Mars.

Moreover, at the beginning of the selection, preparation, and implementation of the first manned space flights in the late $50 \mathrm{~s}$ - early $60 \mathrm{~s}$ of the $20^{\text {th }}$ century, the main problem was to technically carry out the flight of humans into space, to ensure their survival and return to Earth.

At the beginning of the Space Age, no one posed and solved the problem of creating a "cosmic" human, which now, in the 20 s of the $21^{\text {st }}$ century, is becoming a priority for further successful space exploration.

${ }^{1}$ Sergey Krichevsky — professional military pilot and astronaut. In 1989-1998, he was in the Astronaut Corps of the USSR and Russia, preparing for a long flight into space on the Soyuz-TM transport ship and the Mir orbital complex, but did not fly into space. He is a researcher and author of a number of scientific publications on philosophy, history, technologies, problems and the prospects of space exploration, the resettlement of people beyond the Earth, the colonization of space, the exploration of the Moon, the creation of a cosmic state, cosmic humanity and the World Cosmic Union, see: (Krichevsky, 2017, 2019; Krichevsky \& Udartsev, 2019; Krichevsky \& Bagrov, 2019).

${ }^{2}$ The author devotes this article to the anniversaries of the first Astronaut Corps in the USA (1959) and the USSR (1960), the blessed memory of the first astronauts of Earth, the first "cosmic" human in orbit around Earth - Yuri Gagarin (1961), in outer space — Alexei Leonov (1965), on the Moon — Neil Armstrong (1969).

${ }^{3}$ In April 1959, the first NASA Astronaut Corps, the USA (7 people), was created; in March 1960, the first USSR Astronaut Corps (20 people) was ctreated, see: (Ivanova \& Krichevsky, 2013; Krichevsky, 2017, 2019; World Manned Cosmonautics, 2005; Website "ASTROnote Space encyclopedia"; Website of NASA; Website of the Roscosmos; Website "Yu. A. Gagarin Research \& Test Cosmonaut Training Center").

${ }^{4}$ See: (Krichevsky, 2019). 
To successfully solve the problem of creating a new "cosmic" human and effectively manage this process, it is necessary to study a complex set of theoretical and practical scientific, technical, and social-humanitarian issues.

On the $100^{\text {th }}$ anniversary of the beginning of the Space Age in 2057 (in an optimistic scenario) or until the end of the $21^{\text {st }}$ century (in a realistic scenario), one can set an ambitious, but realizable goal: to create an autonomous permanent community of "cosmic" people beyond Earth as the basis for future cosmic humanity.

We will give basic definitions and make a brief analysis of the ideas, technologies, and projects, experience, risks, limitations, and prospects of creating a "cosmic" human, including birth, permanent life, and the possible transformation of people in outer space.

\section{Definitions, ideas, technology, and projects for creating a "cosmic" human}

\section{Definitions and description of the process of creating a "cosmic" human}

A "cosmic" human is the next stage in the evolution of "terrestrial" homo sapiens who realizes, understands their cosmic purpose, is motivated, strives, and is ready to fly into space and live beyond Earth, or the one who was born and continuously lived in the space.

We use the author's approach to the definition and analysis of the process of creation and evolution of cosmic humanity: "Cosmic humanity is (the essence and stages of evolution of human community - human civilization): 1. Humanity, living on Earth, feeling, knowing, understanding its cosmic origin, the relationship with the space, and the cosmic purpose. 2. Humanity living on Earth conducting aerospace activities for the purpose of exploring and using aerospace (Heaven, Cosmos) for survival and development. 3. Humanity, living on Earth and beyond the Earth - in the Solar System, preserving the Earth and mastering space for survival and development. 4. Humanity, settled and living in the space. ... Now, humanity is in the process of transition from the second to the third stage. In the process of this evolution, a complex transformation of man and society takes place" (Krichevsky, 2019: 36-37).

In a similar way, the four stages of the process of creating a new "cosmic" human from "terrestrial" homo sapiens, their further evolution, which is the basis of the future cosmic humanity.

First stage. "A space dreamer living on Earth" - conceived, born, and lives on Earth, is aware of their cosmic mission, motivated, and strives for flights into space and life beyond Earth.

Second stage. "An astronaut from Earth" - conceived, born, lives on Earth, realizes their cosmic mission, motivated, ready, and able to fly into space and live beyond Earth, returning to Earth.

Third stage. "Born and living in space" - conceived, born, lives outside of Earth, is aware of their cosmic mission, motivated, ready and able to fly into space, fly to Earth and return to space, constantly lives beyond Earth in space settlements, which are the communities of people, until the end of their life.

Fourth stage. "An ideal, absolute "cosmic" human" — conceived, born, raised, socialized, adapted, fully realized, and has lived all their life in space, beyond Earth, in space settlements communities of people in near-Earth outer space, on the Moon, Mars, etc.

Thus, an "absolute," fully formed and evolved "cosmic" human is at the fourth stage.

These four stages are interconnected ascending stages of creation and evolution of a "cosmic" human as a complex process of the emergence of new properties and capabilities 
of a "terrestrial" human, the cosmization of individual and social consciousness and activities, genesis and transformation of a "cosmic" human, the expansion of space - the time of existence-being of man in the structures of communities of people, space states, the World Cosmic Union, a new cosmic humanity being created as a cosmic civilization, first on Earth, then on Earth and in near-Earth space, etc. It is followed by permanent life, reproduction, adaptation, and possible further transformation - the evolution of a "cosmic" human beyond Earth in near-Earth space, on the Moon, Mars, the Solar System, Galaxy, and Universe ${ }^{5}$.

Consider the main aspects of the process of creating a "cosmic" human and their evolution.

\section{Ideas and Realities}

The ideas about the life and evolution of humans and humanity in space, creating Cosmic Humanity are reflected in the works and projects of a number of writers, philosophers, scientists, engineers, designers, entrepreneurs, among them: Konstantin Tsiolkovsky, Valentin Lebedev, Sergey Morozov and others. These ideas embrace the whole spectrum of hypotheses about human evolution, situations and possible transformations of homo sapiens in space-time, scenarios, options for their evolution during space exploration, from the perfect and optimistic to catastrophic ones, including the transition to posthuman, cybernetic, non-anthropomorphic species, forms, etc. ${ }^{6}$

It is possible that the modern process of creating a "cosmic" human in the course of space activities of humanity in the $20^{\text {th }}-21^{\text {st }}$ centuries is an attempt of humans' return from Earth to Space, from where they were previously delivered on Earth, but in a different "format."

Modern astronautics, the sphere of space activities reflect and realize the needs of society in the exploration and development of outer space. However, the real process of space exploration is slowing down and lagging behind the plans, paces, and forecasts existing at the beginning of the Space Age.

After euphoria from the outstanding achievements and records of the first flights of people into near-Earth space and to the Moon in the $60 \mathrm{~s}-70 \mathrm{~s}$ of the $20^{\text {th }}$ century, the idea of human expansion into space and the colonization of space lost their former attractiveness. This is due to significant objective technological and economic problems and limitations of space activities, lags in the transition to new technologies, low efficiency in comparison with other industries and fields of activity, growing global problems, and the crisis on Earth. ${ }^{7}$

However, the inhibition of the space exploration process is largely caused by the protracted goal-setting crisis. Outdated goal-setting of the space exploration process prevails in the public consciousness and real politics, people's flights into space continue in the paradigm of demonstrating state flags and new opportunities and records of human and humanity, but the goals of expansion into space are not set for organizing the permanent life of people's communities beyond Earth, colonization of the Moon and Mars.

Permanent life of people in space makes sense and is necessary for two main reasonsfundamentals, according to which the ideas of creating a "cosmic" human can be divided into two main scenarios:

First scenario. Salvation and survival of man and humanity in the event of a global catastrophe on Earth.

\footnotetext{
${ }^{5}$ See: (Krichevsky, 2017, 2019; Krichevsky \& Udartsev, 2019).

${ }^{6}$ See: (Drexler, 1986; Lebedev, 2010; Morozov, 2018; Tsiolkovsky, 1920; Futurology, 2013).

${ }^{7}$ See (Krichevsky, 2019).
} 
Second scenario. Human life, human communities in space (quality, safety, and duration) are acceptable, worthy, not worse, similar or better, more interesting and attractive than on Earth.

These two reasons and two scenarios are the main ones for substantiating the goals and the process of creating a "cosmic" human.

Since the risks of a global catastrophe on Earth exist and are growing. A global catastrophe is inevitable in the future. It is necessary to implement a resettlement scenario, which was called for by Konstantin Tsiolkovsky 100 years ago (1920), describing the process of mass migration of humanity from Earth to space in a science fiction story "Outside The Earth." ${ }^{8}$ Tsiolkovsky and his followers in the $20^{\text {th }}$ century substantiated the need for expansion into space to save not only by the threat of disasters on Earth due to terrestrial and cosmic factors (including asteroid impacts, etc.), but by the overpopulation of Earth due to the rapid population growth and lack of resources and territory, offering to relocate an abundant number of people into space.

By the beginning of the $21^{\text {st }}$ century, it became clear that there was no need and opportunity to resettle people into space due to two important circumstances: 1) a decrease in the growth rate and stabilization of the Earth's population ( $\sim 12$ billion people by the end of the century); 2) lack of technological and economic opportunities for mass expansion and life beyond Earth.

But the main ones are two complex and not yet overcome obstacles: 1) the organization of a safe and dignified permanent life of humans beyond Earth;2) the issues of the possibility of human reproduction, birth, and "raising" children in outer space remain open.

Scenario 1 - saving a human from earthly disasters by expansion into space remains relevant, but its implementation is "frozen." There are significant doubts that in the event of a global catastrophe, humanity will have time and will be able to realize it due to technological and other limitations. Moreover, there are specific projects, for example, the project " 1000 Chinese on Mars", the purpose of which is to create a colony of people on Mars for the subsequent return to Earth and the restoration of humanity after a global catastrophe on Earth. ${ }^{9}$

Scenario 2 - permanent life of people in space in the conditions not worse than on Earth is more likely and feasible than the first scenario, and may also become the beginning for preparing and creating the basis for the implementation of the first scenario. This implies gradual creation of technologies and infrastructure for people's permanent life beyond Earth, and, first, for a small community of people (tens to hundreds) at the third and fourth stages of the "cosmic" human, with further scaling.

\section{Technologies}

There are two interconnected groups of technology for creating a "cosmic" human:

1. Technology for the selection, training of astronauts and other participants in space flights, flying into space on manned spacecraft and stations, ensuring safety and vital functions, medical and biological support, psychological support for people during the flights in near-Earth space, to the Moon, etc., upon returning to Earth, post-flight rehabilitation to restore the human body, etc. Among them, there are a lot of proven, tested, and successfully used technologies, based on which space technology has been created and is being operated in completed and ongoing space projects. Fundamentally new technologies for new space technology and projects for further expansion into space, the birth of children beyond Earth, the development and colonization of the Moon and Mars, permanent life of people in outer

\footnotetext{
${ }^{8}$ See (Tsiolkovskiy, 1920).

${ }^{9}$ By Boris Chertok (Cosmonautics, 2010: 29).
} 
space, etc., including environmentally friendly, clean technologies, have been developed and are being developed. ${ }^{10}$ For space projects, see the Projects section below.

2. Social technologies: space crews, groups and astronauts corps, professional community of astronauts, associations of participants in space flights; space communities; the first space state Asgardia; World Cosmic Union; Cosmic humanity; making Humans a Multi-Planetary Species, etc. ${ }^{11}$

\section{Projects}

Over 60 years, many (hundreds) of projects have been developed regarding the process of creating a "cosmic" human. A number of them have been implemented, some are being implemented, new projects are being prepared, and a significant proportion of such projects are being carried out on Earth to prepare for and provide for people's flights into space, including those for future long missions to the Moon and Mars.

We distinguish three groups of projects aimed at creating a "cosmic" human.

1. Projects of manned space flights on spaceships and stations, of which we single out: the first manned space flight on the Vostok-1 spacecraft (1961, USSR); Apollo program (1968 - 1972, USA), Mir manned space station (1986 - 2001, the USSR and Russia), International Space Station (since 1998, the USA, Russia, the EU, etc.). ${ }^{12}$

2. New projects of manned flights, creation of temporary and permanent stations, bases and settlements for the safe and comfortable life of people in near-Earth space, on the Moon and Mars on the basis of fundamentally new technologies, with the priority of environmentally friendly, clean technologies, for the research, expansion, colonization of space (transport systems; life support systems, artificial gravity, radiation protection; nano-spacesuits; astronaut assistant robots; 3D printers for printing copies of human organs, production and repair of equipment elements, and infrastructure construction using extraterrestrial resources, etc.). ${ }^{13}$

3. Projects of conception, birth, "raising," educating and upbringing of children in space: the international project "Space Travels — Traveling Mentality" (2012); the priority project of the space state of Asgardia on the birth of the first child in space (2019) and other projects of conception and birth of children in space. ${ }^{14}$

\footnotetext{
${ }^{10}$ See (Cosmonautics, 2010; Krichevsky, 2019; Krichevsky \& Bagrov, 2019; World Manned Cosmonautics, 2005; Website "ASTROnote Space encyclopedia"; Website of NASA; Website of the Roscosmos; Website "Yu. A. Gagarin Research \& Test Cosmonaut Training Center").

${ }^{11}$ See (Ivanova \& Krichevsky, 2013; Krichevsky, 2017, 2019; World Manned Cosmonautics, 2005; Website "Asgardia — The Space Nation").

12 See (Cosmonautics, 2010; Dreksler, 1986; World Manned Cosmonautics, 2005; Website "ASTROnote Space encyclopedia"; Website of NASA; Website of the Roscosmos; Website "Yu. A. Gagarin Research \& Test Cosmonaut Training Center").

${ }^{13}$ See (Cosmonautics, 2010; Krichevsky \& Bagrov, 2019; Morozov, 2018; Futurology, 2013; Website of NASA; Website of the Roscosmos; Website "Yu. A. Gagarin Research \& Test Cosmonaut Training Center").

${ }^{14}$ See (Bazaluk, 2012; Edelbroek, 2019; Website “Asgardia — The Space Nation”).
} 
Several countries are conducting research and developments of many new technologies and projects for the expansion of man into space, including the birth of children in space in the next 10-20 years, and a global market for such technologies and services is being formed ${ }^{15}$, but the factors of the space race, competition and commercialization begin to prevail, without the established "rules of the game," restrictions and adequate control, as well as coordination of goals, activities, and resources.

\section{Experience}

Let us give a brief description of the experience of creating a "cosmic" human since 1959: selection, training, space flights, and Earth's long-term life of the astronauts from the USA, the USSR, Russia, the EU, China, and other countries.

About 100 thousand people participated in this process; 1000 of them were selected and trained for flights, of which 565 flew into space (1 to 7 times), including 12 people who have been to the Moon. The record for the duration of a human's continuous stay in space is 438 days (Valery Poliakov, Russia, 1994-1995). In total, the duration of all flights of people in space amounts to $\sim 140$ years. The record for the total duration of manned flights into space is 878 days (Gennadiy Padalka, Russia, 5 flights, 1998-2015). Now there are about 150 "active" astronauts in the world, of which six people are constantly aboard the International Space Station in low Earth orbit, periodically swapping and returning to Earth, usually after $\sim 0.5$ years, others are preparing for flights to ISS or to new spacecraft and for future missions to the Moon and Mars (as of January 1, 2020). Important results have been obtained, but the limitations have been recognized: the properties and characteristics of homo sapiens, the existing risks, technologies and experience of manned space flights so far limit the time for a human to stay safely in outer space: up to $\sim 1.5$ years in zero gravity in orbits $\sim 300-500 \mathrm{~km}$ above Earth and $\sim 3$ days ( $\sim 75$ hours) on the surface of the Moon. ${ }^{16}$

In 1959-1960, when the creation of the first professional astronaut corps in the USA and the USSR began in order to carry out the first manned flights of people into space, their priorities included political, scientific, technical, and military goals and objectives.

The specific goal of creating a "cosmic" human was not set, but the experience of researching and exploring space, analyzing the options for the evolution of humanity on Earth, the development of space technology and activities lead to understanding and recognition first by the leading space states, then by the world community — of the need for raising and solving the problems of "cosmic" human for the expansion into space.

In the natural evolutionary process of creating a "cosmic" human, cosmization, complex socio-cultural transformation of human and society, and the formation of a cosmic subculture took place and are going on in the world. With the start of space flights, the infrastructure for people in outer space is being developed, etc.

The second stage of evolution of the "cosmic" human was reached by about 1000 people who were selected, trained and are prepared for flights, flew and fly into space, are the members of the informal world community of astronauts and are the "core" of the created cosmic humanity. ${ }^{17}$

\footnotetext{
${ }^{15}$ See (Edelbroek, 2019; Website "Asgardia - The Space Nation”).

${ }^{16}$ See (Ivanova \& Krichevsky, 2013; Krichevsky, 2017, 2019; World Manned Cosmonautics, 2005; Website "ASTROnote Space encyclopedia"; Website of NASA; Website of the Roscosmos; Website "Yu. A. Gagarin Research \& Test Cosmonaut Training Center").

${ }^{17}$ See (Ivanova \& Krichevsky, 2013; Krichevsky, 2017, 2019; World Manned Cosmonautics, 2005;
} 
An important role at the second stage was played and is played by the astronaut selection system. But selection is necessary not only to search for the best candidates for professional astronauts: nationwide open contests, peculiar and important tests for the entire society for "cosmic maturity" and the desire to explore and colonize the outer space, as well as the opportunity to widely and publicly promote, especially among young people, the idea of expansion and permanent life off Earth, involving new candidates for "cosmic" people in the process for the first and subsequent stages.

However, until now, the selection and training of astronauts have been performed for timelimited space flights with the subsequent return to Earth, but not for people's permanent life beyond Earth.

We distinguish three main streams of people aspiring into Space: 1) professional crews (pilots, engineers, researchers, payload specialists); 2) space tourists as participants in space flights; 3) "immigrants" for permanent residence from Earth to outer space ${ }^{18}$. Moreover, the third stream (the future "cosmic" children who will be born and will live in outer space) is about to be organized for the implementation of the third and fourth stages of a "cosmic" human.

Asgardia community has been giving new impetus to the development of the ideas and practices of space expansion since 2016, which is an example of self-organization of "cosmic" people of the first stage using information technologies, and since 2017, there has been developed the project of the first digital space state of Asgardia, in which $\sim 1$ million people, a new social structure for active space exploration is being created. ${ }^{19}$

The experience gained testifies to the real existence of a "cosmic" human and communities of such people to a significant scientific, technical, and social-humanitarian potential for further human expansion into space.

\section{Risks and Limitations}

\section{Risks}

We single out and briefly describe the main risks: technical, biomedical, and social.

The risks for human health and life become real and significant at the second stage of the process of creating a "cosmic" human, during the selection and training for space flight on Earth, then they sharply increase during the flights into space, especially during transport operations and transient processes when launching into space and returning to Earth: in 4 out of 319 flights $(\sim 1 \%), 18$ astronauts out of $565 \operatorname{died~}(\sim 3 \%){ }^{20}$

There are two main groups of risks for humans in long space missions due to the influence of two main factors: 1) staying in zero gravity; 2) increased levels of radiation. They both affect humans in space, generating complex negative effects and consequences, including the long-term ones, which are also caused by the individual characteristics of specific people, negatively influence the state of health, life quality, working capacity, increasing the likelihood of dangerous diseases, including cancer, etc. These are the factors and risks that limit the duration of a safe continuous human stay in space.

\footnotetext{
Website "ASTROnote Space encyclopedia"). Unfortunately, many of these "cosmic" people $(\sim 23 \%)$ have already passed away.

${ }^{18}$ The author described it and gave such a classification in 2012, see (Ivanova \& Krichevsky, 2013).

${ }^{19}$ See (Krichevsky, 2017, 2019; Krichevsky and Udartsev, 2019; Website "Asgardia — The Space Nation").

${ }^{20}$ See (World Manned Cosmonautics, 2005; Website “ASTROnote Space encyclopedia”).
} 
People's flights to space are still taking place under conditions of prolonged weightlessness, without artificial gravity systems, which have long been proposed and developed, but have not yet been put into practice. Therefore, astronauts in long flights use special biomedical prophylaxis systems and special diets; do physical exercises on simulators for 2-3 hours every day to counter the destructive processes.

There is still no reliable and effective protection for humans, especially when astronauts work in outer space, from the negative effects of increased levels of primary and secondary radiation in space on modern spacecraft and stations. The increased danger to people in space is represented by periodic flashes of solar activity and streams of high-energy galactic cosmic rays, as well as the internal and external radiation belts of Earth when they intersect in flights in high orbits and beyond its magnetosphere, etc. ${ }^{21}$

However, the risks for humans in space will be especially high with the implementation of the third stage, and a maximum will be reached at the fourth stage of the "cosmic" human. Moreover, at these stages, there is a high probability of acute and chronic diseases, pathologies due to adverse and unpredictable effects and consequences of space factors and technology on the human body, taking into account individual characteristics during conception, the birth of children in space, and permanent life of people in a new environment and new socio-technonatural systems beyond Earth, where fundamentally new extreme and catastrophic situations, events and processes are possible. It may result in a high mortality rate, up to the degeneration of humans in space, and subsequent forced return to Earth.

The questions about the possibility of safe, permanent life of adults in space in conditions of reduced gravity on the Moon (0.16 units) and Mars (0.38 units) in contrast to the Earth (1.0 units) remain open. For the development of a human embryo, the birth and raising of children, apparently, these conditions will be dangerous and unacceptable due to the high risk of developmental pathologies. It seems that for the reproduction and life support of children in space, especially from conception to birth, in the perinatal period and up to 5(?) years, artificial gravity systems and effective radiation protection will be absolutely necessary, constantly providing conditions that are as close as possible to the earthly ones.

It is not known at what levels of gravity adults can safely live permanently in space, including those with constant or periodic use of artificial gravity systems.

Therefore, even at the beginning of the third stage, it will be necessary to deliver adults from Earth for permanent life in conditions of low gravity in near-Earth space, on the Moon and Mars, and also use artificial gravity systems. ${ }^{22}$

In addition to the biomedical and technical risks, social risks are of particular importance. Man on Earth lives in the native and natural environment of the biosphere and the artificial technosphere interconnected with it, existing mainly due to the resources of Earth and its biosphere, i.e., in open systems, which to a large extent provide and guarantee normal human activity (with the exception of places and periods with an unfavorable environment, the negative impact of natural, man-made and other disasters). A human can go beyond Earth only through the social system of civilization using a special space infrastructure and is forced to live in space only in an isolated artificial environment - in the artificial biospheres of manned space objects, promising extraterrestrial space settlements. Therefore, the individual life of a

${ }^{21}$ See (Morozov, 2018; World Manned Cosmonautics, 2005; Website "ASTROnote Space encyclopedia"; Website of NASA; Website of the Roscosmos; Website "Yu. A. Gagarin Research \& Test Cosmonaut Training Center").

${ }^{22}$ See (Morozov, 2018). 
Creation of a "Cosmic" Human: Ideas, Technologies, Projects, Experience, Risks, Limitations, and Prospects by Sergey Krichevsky

"cosmic" human, their safety, and activities in space are even more dependent on society and technology than on Earth.

\section{Limitations}

Hannah Arendt, in her philosophical essay The Conquest of Space and the Stature of Man (1963), made an important analysis of the destructive influence of space exploration on man and our future. Her main idea is that in space, we seemed to have got rid of earthly nature, settled beyond it and are approaching the achievement of the Archimedean point, in which the stature of human ceases to exist $\mathrm{t}^{23}$.

An academician of the Russian Academy of Sciences Nikita Moiseyev, after speaking at the Polytechnic Museum of Moscow (1999), when answering my question about further space exploration by humans, resettlement beyond Earth, said that it was a damping process: human existence and long life further than the Moon were impossible. We are earthly creatures, and in order to live in space, it is necessary to become different, but these creatures will no longer be people. Consequently, further than the Moon, Space can be mastered only by using automatic machines (here is not a quote, but the meaning of what was said is stated, authorial).

There are also more radical views on the necessity and possibility of people flying into space, permanent life of people beyond Earth, proposals for limiting and even completely banning flights of people into space for economic reasons (wastefulness, inefficiency), and also because of negative consequences for life and human health, the threat of "dehumanization" of human, etc. (among their authors are a philosopher Vladimir Kutyrev and an astronomer Vladimir Surdin)..$^{24}$

In essence, man and humanity face an eternal question of being, but in a new "cosmic" interpretation: To be or not to be for a "cosmic" human and cosmic humanity, a cosmic civilization transformed from an earthly human and humanity, in order to survive, develop steadily, and achieve immortality in the Universe?

It is the third stage of the "cosmic" human that is critical to the cosmic future of human and humanity, i.e., their reproduction beyond Earth: it will be necessary to overcome the barrier to reproduction - conception, birth, "raising" of children and their further permanent life in space. There are significant risks and obstacles to this goal (they were described above), and there are great doubts that it will be achieved.

Of particular importance are the advancing development of adequate rules and restrictions, the organization of a permanent safe and dignified life of people in outer space, including the addition, correction, implementation of basic human rights and the principles of bioethics, social guarantees for a "cosmic" human with effective international control.

One of the new restrictions that are already being implemented in the selection and training of astronauts is a genetic restriction that takes into account the risks associated with individual genetic characteristics of the body, for which genetic tests and criteria have been developed. ${ }^{25}$

And, finally, one of the primary and most difficult limitations: a "cosmic" human must remain "themselves," that is, a person, and not become a cyborg, a biorobot, etc. This limitation, which defines the limits of a possible human transformation, including the use

\footnotetext{
${ }^{23}$ See (Arendt, 2014).

${ }^{24}$ See (Krichevsky, 2017).

${ }^{25}$ See (Cosmonautics, 2010; Website "Yu. A. Gagarin Research \& Test Cosmonaut Training Center").
} 
of new technologies: NBICS, robots, artificial intelligence, virtual reality, "hybrid" systems, etc., is extremely important for the implementation of the cosmic future of human and humanity or the transition to posthuman evolution and expansion of mind in the Universe. ${ }^{26}$

\section{Prospects}

The prospects for space exploration and the creation of a "cosmic" human to a large extent depend on the political, social-economic and environmental conditions on Earth, but to a decisive extent - on the development and implementation of fundamentally new technologies for space flights, ensuring safety and comfortable living conditions for people in space, as well as on the anticipatory creation of new social structures - space communities for organizing permanent life beyond Earth. The prospects for creating communities of people beyond Earth are discussed in modern scientific publications at representative international congresses and symposia, for example, in the report of Oleg Orlov and his co-authors: "Humanity is standing at the threshold of a new stage in space exploration - a departure from Earth's orbit to explore the nearest objects in the Solar system, such as the Moon and Mars, with the prospect of building communities on these planetary bodies" (Orlov et al., 2018). ${ }^{27}$ Such new space communities (the space state of Asgardia also refers to them) are the basis for the creation, establishment of a "cosmic" human beyond Earth, and the organization of cosmic humanity. ${ }^{28}$

According to the forecast of a corresponding member of the Russian Academy of Sciences, an astronaut Valentin Lebedev: "The flows of people will increase, and sometime the first human will be born in space. The era of extraterrestrial civilization will begin, rooted in our planet, the crown of which will be formed beyond its borders. For them, the cosmos will become as dear as Earth is for us, but they will remain attached to it so far, like flesh from its flesh. It will demand the development of the science about human evolution in space and their return to Earth - life will turn in a mirror. In the course of settling in the Solar System, a new human environment will develop with its own atmosphere, flora and fauna, and tools. Beyond Earth, the rudiments of society with their genetics, psychology, organization, and culture will appear. The crown of life, when expanding, will give offshoots from those who are born there. It will give rise to the appearance of Man of Space" (Lebedev, 2010).

At present, the process of creating a "cosmic" human is in the transition from the second to the third stage, which can take place before the 100th anniversary of the Space Age in 2057 (optimistic version) or go in cycles and "hang up" at the second stage (pessimistic option).

The "moment of truth" will be the realization of the mass reproduction of people beyond Earth with their further permanent life in space.

New space stations - arks, settlements in near-Earth space, and the Moon as the forefront and the "fulcrum" for human expansion into space, further full exploration and development colonization of the Moon, permanent lunar bases and settlements can and should become spaces for people to live permanently, a new area of their activities and laboratories for a complex and risky test: checking the possibility of creating, surviving and further evolution of a modern "cosmic" human and cosmic humanity, which will determine the future of man and all human civilization on Earth and in outer space. ${ }^{29}$

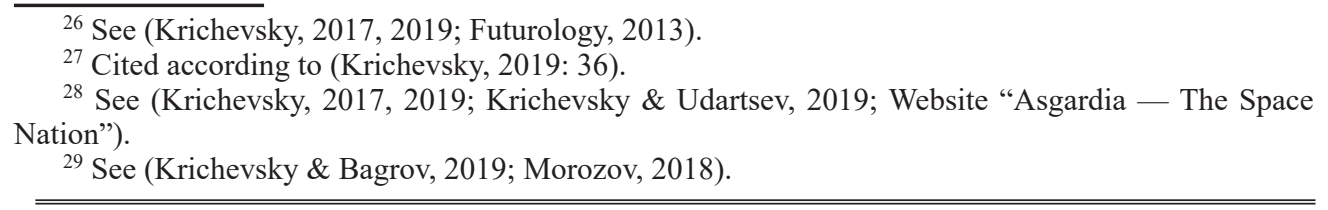


If and when, after a successful mass reproduction in space, "cosmic" children grow up and give birth to their offspring in space, it is possible that the "cosmic" people of new generations will adapt to permanent life under natural low gravity of the Moon and Mars.

At the same time, the scenarios and options are possible, in which a "cosmic" human located at the third and fourth stages will be forced to return to Earth and continue their life on it, actually regressing to the second and first stages. Otherwise, they will continue the expansion process and then transform into a posthuman with further evolution along the trajectory, which we will represent as a hypothetical "futurological chain" of ideas - forecasts: "astronaut quasi-human" (after Yuri Baturin and Oleg Dobrochev, 2010), "cosmic universal human" (after Sergey Krichevsky, 2010, 2012), "cybernetic immortal human" (after Dmitry Itskov, 2012), "radiant human" in "radiant humanity" (after Konstantin Tsiolkovsky, the 1930s), "post-posthuman, living universal rational being" (after Sergey Krichevsky, 2013). ${ }^{30}$

$$
* * *
$$

Humanity has a "window of opportunity" for creating a "cosmic" human and expansion into space. In order to manage the process, it is necessary to develop and implement a single international megaproject as a part of the super-global project "Cosmic Humanity," during which to create a set of new technologies for ensuring safety and life on the full cycle of human life in space (from conception to death), taking into account the impact of adverse factors, complex and poorly studied biological, psychological, socio-cultural and other aspects of human adaptation, their possible transformation and further evolution into cosmos in the new socio-techno-environment.

Human civilization is "pregnant," and an important historical event will happen soon: the birth of the first human - a "cosmic" child outside of Earth.

But the main question remains open: will the idea of human expansion into space in the coming years or decades of the $21^{\text {st }}$ century spread on Earth and get real necessary and sufficient political, legal, economic and technological support from space states and corporations, space, scientific and other communities of the Earthly humanity - the world community represented by the UN and other influential institutions?

\section{Conclusions}

1. For effective space exploration and the creation of cosmic humanity for the survival and development of humanity within the scope "Earth + Space," the world community under the auspices of the UN will have to solve the key and complex problem of creating a "cosmic" human capable of reproduction and permanent life beyond Earth, with using new technologies, technical and social systems.

2. The definition of a "cosmic" human is proposed, and the periodization of the process of their creation in the form of four stages is made. The foundations of a new concept are outlined.

3. Over 60 years, the world has gained considerable experience in the selection and training of astronauts, their vital functions; important results have been achieved in space flights, but the limits have been reached: human properties and characteristics, existing risks, technologies and experience currently limit the duration of continuous safe stay in space, the scale and the pace of space exploration.

\footnotetext{
${ }^{30}$ According to (Krichevsky, 2019: 47).
} 
4. It is necessary to go beyond these limits, to set new goals and develop new projects, to ensure security, human development and transformation using new technologies, to develop and implement fundamentally new technologies and projects for creating the objects - settlements in near-Earth space, on the Moon, on Mars, with the organization of vital activity, the full cycle of human life, communities of people in space. Critical to the cosmic future of humans and humanity is the third stage of the creation of the "cosmic" human - their reproduction beyond Earth.

5. In order to manage the process of creating a "cosmic" human, it is necessary to develop and implement a single international megaproject as a part of the superglobal project "Cosmic Humanity," during which to create a set of new technologies for ensuring safety and life on the full cycle of human life in space.

6. Particular importance is attached to the accelerated development of adequate rules and restrictions, organization of permanent safe and dignified life of people in space, including addition, correction, implementation of basic human rights and bioethics principles, social guarantees for a "cosmic" human with effective international control. It is also necessary to correct the system of selection, training, organization of the activities of astronauts, participants in space flights - everyone who will fly beyond Earth and then will permanently live in space.

7. New space stations - arks, settlements in near-Earth Space and the Moon as a forefront and a "fulcrum" for human expansion into space, further full exploration and development - colonization of the Moon, permanent lunar bases and settlements can and should become places for permanent life of people, a new area of their activities and laboratories for a difficult and risky test: checking the possibility of creating, surviving and further evolution of a new "cosmic" human and cosmic humanity, which will be the "moment of truth" for the future man and all human civilization on Earth and in outer space.

8. It is proposed to organize a special International Center (Institute) for the research on the theoretical and practical aspects of the process of creation, formation, and evolution of a "cosmic" human.

\section{References}

Arendt, Hannah (2014) Between the past and the future. Moscow: Gaidar Institute Publishing House. (In Russian).

Bazaluk, Oleg (2012) Space Travels - Traveling Mentality. The course of lectures. Kyiv: KNT. (In Russian).

Cosmonautics of the 21 $1^{\text {st }}$ century: Attempt of the Forecast of Development till 2101 (2010) Ed. by Boris Chertok. Moscow: RTSoft. (In Russian).

Drexler, K. Erik (1986) Engines of Creation. The Coming Era of Nanotechnology. New York: Anchor Books.

Edelbroek, Egbert K.A. (2019) SpaceBorn United company: Missions Planned for Human Conception and Childbirth in Space. Aerospace Sphere Journal. 4, 26-36. https://doi. org/10.30981/2587-7992-2019-101-4-26-36 (In Russian).

Ivanova, Lidia, and Sergey Krichevsky (2013) The community of astronauts. History of formation and development for half a century. Problems and prospects. Foreword by Viktor Savinykh. Moscow: LIBROKOM. (In Russian). 
Krichevsky, Sergey (2017) Cosmic Humanity: Utopia, Realities, Prospects. Future Human Image, 7, 50-70.

Krichevsky, Sergey (2019) Cosmic Union of Communities: a New Concept and Technologies of Creating Cosmic Humanity. Philosophy and Cosmology, Vol. 22, 33-50. https://doi. org/10.29202/phil-cosm/22/4

Krichevsky, Sergey and Sergey Udartsev (2019) Space State on Earth and Beyond: Philosophy, Models, Experience, and Prospects. Philosophy and Cosmology, Vol. 23, 30-52. https:// doi.org/10.29202/phil-cosm/23/4

Krichevsky, Sergey, and Alexander Bagrov (2019) Moon Exploration: Legal Aspects. Advanced Space Law, Vol. 4, 34-49. https://doi.org/10.29202/asl/2019/4/4

Lebedev, Valentin (2010) Man of Space. Science and life, 2, 42-44. https://www.nkj.ru/archive/ articles/17349/ (In Russian).

Morozov, Sergey (2018) Homeostatic Arc as the Main Means in the Strategy of Space Exploration. Aerospace Sphere Journal, 3, 28-37. https://doi.org/10.30981/2587-79922019-98-1-82-94 (In Russian).

Futurology. $21^{\text {st }}$ century: immortality or global catastrophe? (2013) Alexey Turchin and Mikhail Bakhtin. Moscow: BINOM.

Tsiolkovsky, Konstantin. (1920) Outside The Earth. Kaluga: Publication of the Kaluga society for the study of nature and the local region. (In Russian).

Website "Asgardia — The Space Nation." https://asgardia.space/

Website "ASTROnote Space encyclopedia." http://astronaut.ru/index.htm

Website of NASA (USA). https://www.nasa.gov/

Website of the Roscosmos State Corporation for Space Activities (ROSCOSMOS). https:// www.roscosmos.ru/

Website "Yu. A. Gagarin Research \& Test Cosmonaut Training Center". http://www.gctc.su/

World Manned Cosmonautics (History. Technology. People) (2005) Ed. by Yuri Baturin. Moscow: RTSoft. (In Russian). 